\title{
CHALLENGES AND TASKS IN MEDICAL CARE FOR CHILDREN WITH AUTISM SPECTRUM DISORDER IN RUSSIA
}

\author{
NATALIA USTINOVA, MD, PHD, HEAD OF LABORATORY OF SOCIAL PEDIATRICS
}

OBJECTIVES: Detection of problems in medical care for children with ASD in Russia and suggestions to solution.

BACKGROUND: ASD is a multifaceted problem. Recent studies have shown specific medical comorbidities in autism. According to official statistics only 1 in 1000 children has an ASD in Russia. It means that too many children lacks proper health care.

MATERIALS AND METHODS: Interviews of 161 parents of children with ASD (30 months - 7 years old, mean age 48 months, $S D=6)$, working group discussion with experts (pediatricians, psychiatrists, child neurologists, gastroenterologists, public health professionals, nutritionists) and parents.

RESULTS:

Psychiatric services problems: services are separated from other medical facilities; there are no cooperation between pediatricians and psychiatrists or neurologists and psychiatrists; unreasonable hospitalizations; psychiatrists are not familiar with somatic comorbidity in autism and consider some medical signs (for example selectivity in food) as a psychopathology; adherence to an outdated conceptions, ignoring modern approaches to classification and treatment; overuse of psychotropic medications; parents perceive contacts with psychiatric services as an extreme step and as a stigma.

Medical services problems: doctors are not acquainted with ASD signs and screening instruments for autism risk; doctors are not acquainted with specific comorbidity in ASD; doctors are not acquainted with impact of somatic disorders on child behavior; there are no trained specialists for preparing children with ASD for medical procedures. As a result: ASD is diagnosed later than required; concomitant somatic pathology is not treated.

Ekaterina Men,

President of autonomous non-profit organization "Center for Autism Problems" and her son Platon



"I began to suspect that my child had autism when he was 1 year 10 months old, but for a long time struggled with doctors who denied this diagnosis and said "don't worry", "he will outgrow" and so on»
CONCLUSION It is necessary to establish multidisciplinary team (psychiatrist, pediatrician and other medical specialists) in pediatric setting. The staff have to be trained in maintenance of children with ASD in pediatric setting (preparation for procedures); signs of autism, behavioral problems; comorbidity in autism and treatment.

Approbation of multidisciplinary model for medical care of ASD was approved by the Ministry of Health of Russian Federation. After that, model can be spread throughout Russian pediatric settings.

\section{Some questions from parents interview}

Q. Who the first paid attention to development delay/deviation of your child?

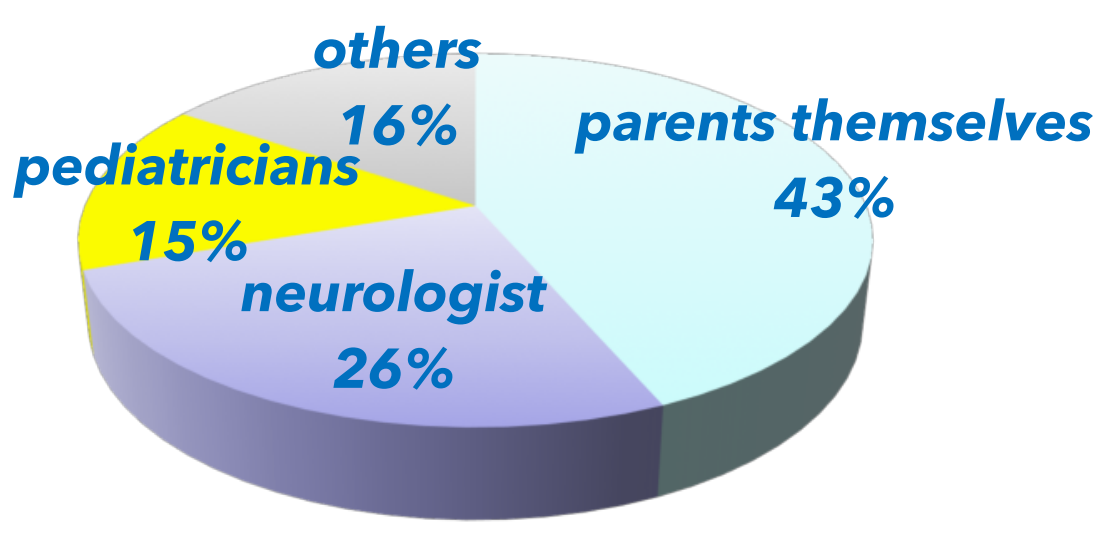

Q. Do you think the diagnosis of ASD could have been made earlier in a pediatric clinic with trained multidisciplinary team rather than in a psychiatric facility?

\begin{tabular}{|c|c|}
\hline "YES" & "NO" \\
\hline $82,6 \%$ & $17,4 \%$ \\
\hline
\end{tabular}

Q. At the first visit to a psychiatrist, was it recommended:

a) hospitalization

\begin{tabular}{|c|c|}
\hline "YES" & "NO" \\
\hline $91,3 \%$ & $8,7 \%$ \\
\hline
\end{tabular}

b) neuroleptic treatment

\begin{tabular}{|c|c|}
\hline "YES" & "NO" \\
\hline $83,2 \%$ & $16,8 \%$ \\
\hline
\end{tabular}

Q. Did your child make any gastrointestinal complaints (limited range of products, food selectivity, decreased or increased appetite, constipation, diarrhea, nausea, upset stomach etc.)?

\begin{tabular}{|c|c|}
\hline "YES" & "NO" \\
\hline $79,5 \%$ & $20,5 \%$ \\
\hline
\end{tabular}

If "YES", did your child receive appropriate medical examination and treatment?

\begin{tabular}{|c|c|}
\hline "YES" & "NO" \\
\hline $53,1 \%$ & $46,9 \%$ \\
\hline
\end{tabular}

